\title{
The Study of Functional Outcome of Lumbar Spine Disorders Treated with Laminectomy: The Surgical Management
}

\author{
Dr Harikiran Bangera \\ Assistant Professor, Department of Orthopedics, Srinivas Institute of Medical Sciences, Mangalore
}

\begin{abstract}
The central spinal stenosis denotes the involvement of the area between the facet joints, which includes dura and its contents. the reasons for the stenosis here are protrusing disc, bulging annulus, osteophyte formation or thickened ligamentumflavumcental canal stenosis clinically presents as claudication and the lateral canal stenosis presents as radiculopathy the lateral recess also referred as lee's entrance zone, begins from lateral border of dura and extends to medial border of pedicle. This is where the nerve root exits. Zones of lateral canal is divided into entrance zone, mid zone and the exit zone the reason for stenosis here are lateral disc herniation, thickened ligamentumflavum extending into the foramen, facet arthritis or spondylolisthesis. Laminectomy is the procedure of choice especially in the elderly. The present study is done to find out the functional outcome of lumbar spine disorders treated with laminectomy.
\end{abstract}

Keywords: Functional Outcome, Lumbar Spine Disorder, Roland Morris Score

\section{Introduction}

Park et $\mathrm{al}^{12}$ did retrospective comparative study looking at the SPORT study results to determine the effect of multilevel stenosis on surgical and conservative treatment outcomes. Patients with multiple levels of stenosis had somewhat less severe pain at baseline on the SF-36 bodily pain scale compared to one and two levels. Patients with single level stenosis were less likely to present with neurogenic claudication $(\mathrm{p}<0.001)$ and more likely to report dermatomal pain radiation. Other baseline symptoms were similar across groups. When comparing surgical to conservative treatments for one, two and three level isolated stenosis, there was a significant surgical treatment effect in most outcomes measures within each subgroup at each time point. The only significant difference in treatment effects between subgroups was at two years for patient satisfaction with symptoms.

Laminectomy is the procedure of choice especially in the elderly. The central spinal stenosis denotes the involvement of the area between the facet joints, which includes dura and its contents. the reasons for the stenosis here are protrusing disc, bulging annulus, osteophyte formation or thickened ligamentumflavumcental canal stenosis clinically presents as claudication and the lateral canal stenosis presents as radiculopathy the lateral recess also referred as lee's entrance zone, begins from lateral border of dura and extends to medial border of pedicle. This is where the nerve root exits. Zones of lateral canal is divided into entrance zone, mid zone and the exit zone the reason for stenosis here are lateral disc herniation, thickened ligamentumflavum extending into the foramen, facet arthritis or spondylolisthesis $^{1-10}$.

Weinstein $\mathrm{JN}$, et $\mathrm{al}^{11}$.combined the randomized and observational cohorts of patients with spinal stenosis (SpS), those treated surgically showed significantly greater improvement in pain, function, satisfaction, and self-rated progress over four years compared to patients treated non- operatively. Results in both groups were stable between two and four years.

Patients with single level stenosis had a smaller difference in satisfaction between surgery and conservative treatment, that is, a smaller treatment effect than the other two groups. This study provides Level III therapeutic evidence that patients with spinal stenosis without associated degenerative spondylolisthesis or scoliosis can be managed nonoperatively irrespective of the number of levels involved. Surgical intervension never affects the number of level of the spinal stenosis.

Amundsen et $\mathrm{al}^{13}$ dis a case control, comparative study of 100 patients with symptomatic spinal stenosis

Atlas SJ et al ${ }^{14}$ did a study on long term outcome of surgical and non surgical management of lumbar canal stenosis 8 to 10 years of follow-up. A prospective observational cohart study Of 148 eligible consenting patients initially enrolled, 105 were alive after 10 years $(67.7 \%$ survival rate). Among surviving patients, long-term follow-up between 8 and 10 years was available for 97 of $123(79 \%)$ patients (including 11 patients who died before the 10-year follow-up but completed a 8 or 9 year survey); 56 of $63(89 \%)$ initially treated surgically and 41 of $60(68 \%)$ initially treated nonsurgically. Patients undergoing surgery had worse baseline symptoms and functional status than those initially treated nonsurgically. Outcomes at 1 and 4 years favored initial surgical treatment. After 8 to 10 years, a similar percentage of surgical and nonsurgical patients reported that their low back pain was improved (53\% vs. $50 \%, \mathrm{P}=0.8)$, their predominant symptom (either back or leg pain) was improved (54\% vs. $42 \%, \mathrm{P}=0.3$ ), and they were satisfied with their current status $(55 \%$ vs. $49 \%, \mathrm{P}=0.5)$. These treatment group findings persisted after adjustment for other determinants of outcome in multivariate models. However, patients initially treated surgically reported less severe leg pain symptoms and greater improvement in back-specific

\section{Volume 6 Issue 12, December 2017}




\section{International Journal of Science and Research (IJSR) \\ ISSN (Online): 2319-7064}

Index Copernicus Value (2016): 79.57 | Impact Factor (2015): 6.391

functional status after 8 to 10 years than nonsurgically treated patients.

The present study is done to find out the functional outcome of lumbar spine disorders treated with laminectomy.

\section{Aims and Objectives}

To study of functional outcome of lumbar spine disorders treated with laminectomy.

\section{Materials and Methods}

This study was done in Department of Orthopedics, Srinivas Institute of Medical Sciences, Mangalore. Thirty people who were treated with laminectomy procedures were selected randomly and the functional scores were studied.

\section{Inclusion criteria}

1. Degenerative Lumbar spine stenosis

\section{Exclusion criteria}

1. Old fracture spine

The statistical Analysis was done using the latest SPSS software 2015 California.

\section{Results}

Table 1: SLRT

\begin{tabular}{|c|c|}
\hline SLRT & Surgical \\
\hline $20-29$ & 3 \\
\hline $30-39$ & 10 \\
\hline $40-49$ & 4 \\
\hline $50-59$ & 6 \\
\hline $60-69$ & 5 \\
\hline $70-79$ & 2 \\
\hline
\end{tabular}

Table 2: Femoral Stretch test

\begin{tabular}{|c|c|}
\hline FST & Surgical \\
\hline Yes & 26 \\
\hline No & 4 \\
\hline
\end{tabular}

Table 3: Extensor Hallusis Longus Power

\begin{tabular}{|c|c|}
\hline EHL & Surgical \\
\hline Grade III Right & 3 \\
\hline Grade IV B/L & 2 \\
\hline Grade IV Left & 14 \\
\hline Grade IV Right & 11 \\
\hline
\end{tabular}

Table 4: Flexor HallusisLongus Power

\begin{tabular}{|c|c|}
\hline FHL & Surgical \\
\hline Grade IV Left & 4 \\
\hline Grade V B/L & 26 \\
\hline
\end{tabular}

Table 4: Spine Flexion

\begin{tabular}{|c|c|}
\hline Spine Flexion & Surgical \\
\hline Restricted & 21 \\
\hline Not Restricted & 09 \\
\hline
\end{tabular}

\section{Discussion}

Twenty-two patients were assigned to each group. Only 32 of 44 patients were randomly assigned into each group. The mean functional status at one year was improved in both groups. Conservative treatment consisted of bed rest, use of a semirigidorthosis, physical therapy and appropriate exercise program. Mariconda et $\mathrm{al}^{15}$ reported an incompletely randomized, prospective study of 44 patients comparing single or multilevel laminectomy in patients with mild to moderate leg pain to patients treated with medical/ interventional therapy. Outcomes were assessed using the Beaujon Scoring System. At four years, the good results were $68 \%$ in the surgical group and $33 \%$ in the medi-cal/ interventional group. Only $2.6 \%$ of patients experienced an increase in their spondylolisthesis. There was a reoperation rate of $9 \%$ and a cross over rate of $9 \%$. Arinzonet $\mathrm{al}^{14}$ performed a prognostic case control studies investigating the effect of decompression for lumbar spinal stenosis in elderly diabetic patients.

Arinzonet $\mathrm{al}^{16}$ did a retrospective, prognostic study of the effects of age on decompressive surgery for lumbar spinal stenosis. 283 patients were grouped according to age. One group was aged 65-74 years old and the second group was > 75-years-old. Follow-up was up to 42 months with a minimum of nine months. Within both treatment groups there was a significant $(\mathrm{p}<0.0001)$ subjective improvement in low back and radicular pain as well as the ability to perform daily activities. When compared to preoperative levels, the oral scores for pain while performing daily activities were significantly improved $(\mathrm{p}<0.001)$ in both treatment groups. The authors concluded that the overall postoperative complication rate was similar between the groups and that age is not a contraindication for surgical decompression of lumbar spinal stenosis. Both groups are equally likely to suffer minor perioperative complications.

The study included 62 diabetic patients and 62 gender- and age-matched non diabetic controls. The mean follow-up was 40.3 months. Comorbidities were as assessed and outcomes were measured using the visual analog scale (VAS), basic activities of daily living (BADL) and walking distance. The authors concluded that decompression for symptomatic spinal stenosis is beneficial in elderly diabetic patients. However, the results are related to successful pain reduction, physical and mental health status, severity of clinical presentation, insulin treatment and duration of diabetes. The benefits in diabetic patients are low as compared with non diabetic patients with regard to symptom relief, satisfaction, BADL function and rate of complications.

\section{Conclusion}

In this study the functional outcome was better for a period of 6 months after surgery.

\section{References}

[1] Svensson HO, Andersson GB. Low-back pain in 40- to 47-year-old men: work history and work environment factors. Spine. 1983 Apr;8(3):272-6. 


\section{International Journal of Science and Research (IJSR) \\ ISSN (Online): 2319-7064 \\ Index Copernicus Value (2016): 79.57 | Impact Factor (2015): 6.391}

[2] Svensson HO, Andersson GB. The relationship of lowback pain, work history, work environment, and stress. A retrospective cross-sectional study of 38- to 64-yearold women. Spine. 1989 May;14(5):517-22.

[3] PFU Jr, MD, Orthopedic Surgeon. Lumbar Spinal Stenosis: A Definitive Guide [Internet]. Spine-health. [cited 2016 Nov 25]. Available from: http://www.spinehealth.com/conditions/spinal-stenosis/lumbarspinalstenosis-a-definitive-guide

[4] Medtronic. Lumbar Spinal Stenosis Treatment \& Symptoms | Back.com [Internet]. [cited 2016 Nov 25]. Available from: http://www.back.com/backpain/conditions/lumbar-spinalstenosis/index.htm

[5] Ise S, Abe K, Orita S, Ishikawa T, Inage K, Yamauchi $\mathrm{K}$, et al. Surgical treatment for far-out syndrome associated with abnormal fusion of the L5 vertebral corpus and L4 hemivertebra: a case report. BMC Res Notes [Internet]. 2016 Jun 28 [cited 2016 Nov 26];9. Available from: http://www.ncbi.nlm.nih.gov/pmc/articles/PMC492430 8/

[6] Atlas SJ, Keller RB, Wu YA, Deyo RA, Singer DE. Long-term outcomes of surgical and nonsurgical management of lumbar spinal stenosis: 8 to 10 year results from the maine lumbar spine study. Spine. 2005 Apr 15;30(8):936-43.

[7] Caputy AJ, Luessenhop AJ. Long-term evaluation of decompressive surgery for degenerative lumbar stenosis. J Neurosurg. 1992 Nov 1;77(5):669-76.

[8] The Natural Course of Lumbar Spinal Stenosis. : Clinical Orthopaedics and Related Research [Internet]. LWW. [cited 2016 Dec 1]. Available from: http://journals.lww.com/corr/Fulltext/1992/06000/The_ Natural_Cours e_of_Lumbar_Spinal_Stenosis_.10.aspx

[9] Yuan PS, Booth RE, Albert TJ. Nonsurgical and surgical management of lumbar spinal stenosis. Instr Course Lect. 2005;54:303-12.

[10] Roland Morris Disability Questionnaire [Internet]. [cited 2016 Dec 1]. Available from: http://www.rmdq.org/

[11] Weinstein JN, Lurie JD, Tosteson TD, Skinner JS, Hanscom B, Tosteson ANA, et al. Surgical vsnonoperative treatment for lumbar disk herniation: the Spine Patient Outcomes Research Trial (SPORT) observational cohort. JAMA. 2006 Nov 22;296(20):2451-9.

[12] Park DK, An HS, Lurie JD, Zhao W, Tosteson A, Tosteson TD, et al. Does multilevel lumbar stenosis lead to poorer outcomes?: a subanalysis of the Spine Patient Outcomes Research Trial (SPORT) lumbar stenosis study. Spine. 2010 Feb 15;35(4):439-46.

[13] Amundsen $T$, Weber $H$, Nordal HJ, Magnaes $B$, Abdelnoor M, Lilleâs F. Lumbar spinal stenosis: conservative or surgical management?: A prospective 10-year study. Spine. 2000 Jun 1;25(11):1424-14351436.

[14] Atlas SJ, Keller RB, Wu YA, Deyo RA, Singer DE. Long-term outcomes of surgical and nonsurgical management of lumbar spinal stenosis: 8 to 10 year results from the maine lumbar spine study. Spine. 2005 Apr 15;30(8):936-43.

[15] Epstein NE. Spine surgery in geriatric patients: Sometimes unnecessary, too much, or too little.
SurgNeurolInt [Internet]. 2011 Dec 31 [cited 2016 Nov 29];2.

Volume 6 Issue 12, December 2017 